\title{
Institutions and Individuals: Interaction and Evolution
}

\author{
Geoffrey M. Hodgson
}

16 May 2006

Published in Organization Studies, January 2007

\begin{abstract}
The Business School, University of Hertfordshire, De Havilland Campus, Hatfield, Hertfordshire AL10 9AB, UK http://www.herts.ac.uk/business http://www.geoffrey-hodgson.ws

Address for correspondence:

Malting House, 1 Burton End, West Wickham, Cambridgeshire CB1 6SD, UK

g.m.hodgson@herts.ac.uk
\end{abstract}

\begin{abstract}
The conceptualization of the relation between individual and structure is central to social science. After making some key definitions, this paper overviews some recent developments in the social theory of structure and agency, and makes a novel addition, based on a concept of habit derived from pragmatism and Veblenian institutional economics. Processes of habituation provide a mechanism of 'reconstitutive downward causation' where institutional circumstances may affect individual preferences. Finally, special characteristics of organizations are discussed, endorsing an evolutionary analytical approach that combines insights from both evolutionary economics and organization science.
\end{abstract}

KEY WORDS: Organizations, institutions, structures, methodological individualism, downward causation, habits, routines, evolution

BIOGRAPHICAL NOTE: Geoffrey M. Hodgson is a Research Professor in Business Studies at the University of Hertfordshire in Hatfield, England. He is Editor in Chief of the Journal of Institutional Economics. His books include Economics in the Shadows of Darwin and Marx (2006), The Evolution of Institutional Economics (2004), How Economics Forgot History (2001), and Economics and Utopia (1999). He has published widely in the academic journals, as detailed on his website www.geoffrey-hodgson.info 


\title{
Institutions and Individuals: Interaction and Evolution
}

\author{
Geoffrey M. Hodgson
}

The relationship between social structure and individual agency is one of the central problems in social theory. Sometimes described otherwise, such as the rivalry between accounts based on 'situation' or 'disposition', it pervades methodological discussion in organization studies and elsewhere. ${ }^{1}$ It has major implications for theoretical and empirical research. However, there have been attempts by post-modernists and post-structuralists to dismiss or transcend this issue. In response, Nicos Mouzelis (1995, pp. 69-70) assessed 'attempts to dismiss the agency-structure distinction ... either by conflating the two notions, or by ... deriving the one from the other' as leading to a theoretical impasse. Notably, many of these evasive attempts involve 'the reintroduction of the distinction by the back door ... by keeping the logic of the agent-structure dichotomy while expressing it through a different terminology'. The solution to the agency-structure problem is not to walk away from it, or to pretend it does not exist. Such strategies have notably ended up with the readmission of the problem in another form.

This essay takes the agency-structure problem as axiomatic and takes a fresh look at some of the issues. Two major lines of argument are emphasized. The first involves a critique of what is sometimes described as methodological individualism, involving reductionist claims that structures, institutions or organizations must be analyzed largely or wholly in terms of individuals and their properties.

The second line of argument involves a radical transformation of the conception of the human agent, in contrast to prevailing conceptions in both mainstream economics and sociology. Taking inspiration from pragmatist philosophy and psychology, and from the institutional economics of Thorstein Veblen $(1914,1919)$, habit is reinstated as a core dispositional mechanism underlying actions and beliefs. ${ }^{2}$ As demonstrated below, this has important implications for the agency-structure problem.

Before these arguments are developed some terminological issues require attention. What is the difference between structures, institutions, conventions and organizations? As elaborated elsewhere (Hodgson, 2006), these terms are used in the following way:

- Social structures include all sets of social relations, including the episodic and those without rules, as well as social institutions.

- Institutions are systems of established and embedded social rules that structure social interactions.

\footnotetext{
1 The author is very grateful to Howard Aldrich, Markus Becker, Thorbjørn Knudsen and Jan-Willem Stoelhorst for comments on a previous draft of this paper.

2 The origins and evolution of Veblenian institutional economics are set out in Hodgson (2004). This essay makes use of some material from that book.
} 
- Rules in this context are understood as socially transmitted and customary normative injunctions or immanently normative dispositions, that in circumstances $X$ do $Y$.

- Conventions are particular instances of institutional rules.

- Organizations are special institutions that involve (a) criteria to establish their boundaries and to distinguish their members from non-members, (b) principles of sovereignty concerning who is in charge and (c) chains of command delineating responsibilities within the organization.

According to these definitions, organizations are a subset of the set of institutions, and institutions are a subset of the set of social structures. ${ }^{3}$ An example of a social structure that is not an institution is a demographic structure (Archer, 1995). Because of their established and relatively durable nature, institutions are the most general social structures relevant to the discussion here. Language is an example of an institution that is not an organization. The rule that infinitives should not be split is a convention within the institution of the English language. Every business firm is simultaneously an organization, institution and structure.

The additional features that are definitional for organizations are not central to the main argument here but they are nevertheless very important for understanding interactions between organizations and individuals. I shall briefly mention some of the implications of these additional features towards the end of this essay.

Eight sections follow. Sections 1-4 review concepts that are familiar in social theory, but are still widely disputed. They are important to prepare the ground for the distinctive contribution in the final sections. Sections 1-2 criticize methodological individualism and methodological collectivism respectively. Section 3 defines and criticizes reductionism. Section 4 reviews the work of Giddens, which attempts to surpass both methodological individualism and methodological collectivism. Section 5 examines some problems in critical realism, which lead to the crucial concept of habit promoted in section 6. In sections 6-7 it is shown that habits provide a mechanism of 'reconstitutive downward causation' through which social circumstances can affect individual purposes and preferences. The concluding section draws out some implications for the social sciences in general and organization studies in particular.

\section{Problems with Methodological Individualism}

Typically, methodological individualists propose that social structures, institutions, and other collective phenomena should be explained in terms of the individuals involved. ${ }^{4}$ However, there is far from agreement on the precise definition of this term (Udéhn, 2001).

Consider some examples. For the Austrian School economist Ludwig Lachmann (1969, p. 94) methodological individualism means 'that we shall not be satisfied with any type of

\footnotetext{
3 Searle (2005) has a different definition of institutions but there is some consonance with his approach. Ostrom (2005) provides a forensic discussion of the nature of rules. Hodgson (2006) demonstrates that Douglass North regards organizations as institutions, contrary to a widespread misinterpretation.

4 Note that methodological individualism is about explanation. It is different from ontological individualism, which would involve the statement that 'society consists of individuals', and from political individualism, which emphasizes individual rights.
} 
explanation of social phenomena which does not lead us ultimately to a human plan.' But very few social scientists would deny the role of individual intentions in the explanation of social phenomena.

In another attempt Jon Elster (1982, p. 453) defines methodological individualism as 'the doctrine that all social phenomena (their structure and their change) are in principle explicable only in terms of individuals - their properties, goals, and beliefs.' Being less banal, this definition also is insufficiently precise, as it fails to clarify whether interactions between individuals or social structures are 'properties ... of individuals' or not. If individual interactions or social structures are not 'properties of individuals', then this narrower and more meaningful notion of methodological individualism must be deemed inoperable, for the reasons given below. On the other hand, if individual interactions or social structures are among the 'properties of individuals' then Elster's statement is acceptable. The only question is why this is described as 'individualism' when the 'properties of individuals' also include structures.

Overall, much of the confusion in the debate over methodological individualism stems from whether methodological individualism means one or other of the following:

(a) social phenomena should be explained entirely in terms of individuals alone; and

(b) social phenomena should be explained in terms of individuals plus relations between individuals.

The first of these versions (a) has never been achieved in practice, for reasons given below. By contrast, the problem with the second version (b) is that not that it is wrong but the term 'methodological individualism' is unwarranted. Let us expand on these arguments, taking each version in turn.

Why has the explanatory reduction to individuals alone in version (a) never been achieved? Neoclassical economics may claim to have achieved such a reduction. However, leading economist and Nobel Laureate Kenneth Arrow (1994) denies this, by pointing out that the price mechanisms in neoclassical theory involve social interactions and structures, and social phenomena that cannot be reduced entirely to individuals alone. Arrow (1994, pp. 4-5) remarked 'economic theories require social elements as well even under the strictest acceptance of standard economic assumptions ... individual behavior is always mediated by social relations. These are as much part of the description of reality as in individual behavior.'

All versions of social contract theory involve individuals communicating with others or, at least, adopting tacit presumptions of the intentions and stances of others. All such interactions presume rules of interaction or interpretation. Communication involves some form of language, and languages by their nature are systems of rules. Hence social contract theory and general equilibrium theory both presume structured relations between individuals, rather than individuals in isolation.

Individual choice requires a conceptual framework to make sense of the world. The reception of information by an individual requires a paradigm or cognitive frame to process and make sense of that information. The acquisition of this cognitive apparatus involves processes of socialization and education, involving extensive interaction with others (Mead, 1934; Fleck, 1979; Douglas, 1986; Hodgson, 1988; Bogdan, 2000). The means of our understanding of the world are necessarily acquired through social relationships and interactions. Cognition is a social as well as an individual process. Individual choice is impossible without these institutions and interactions. 
Alexander Field (1979) has shown that attempts by economists to explain the origin of social institutions always presume individuals acting in a particular context, with rules of behaviour governing their interaction. In the presumed 'state of nature' from which institutions are seen to have emerged, a number of weighty rules, structures and cultural and social norms have already been (implicitly or explicitly) assumed. Accordingly, with explanations of the origin of institutions through game theory, Field pointed out that several constraints norms and rules must inevitably be presumed at the start. There can be no games without constraints or rules, and thus game theory can never explain the elemental constraints or rules themselves. Even in a sequence of repeated games, or of games about other (nested) games, at least one game or meta-game, with a structure and payoffs, must be assumed at the outset.

Similarly, Kyriakos Kontopoulos (1993, p. 79) noted that 'a methodological individualist strategy necessarily incorporates references to social relations'. As these critics have showed, claimed methodological individualists never start from individuals alone. For example, Steven Lukes (1973, pp. 121-2) shows that in the claimed 'methodological individualism' of Karl Popper (1945), 'the social phenomena have not really been eliminated; they have been swept under the carpet'. We always have to assume relations between individuals, as well as individuals themselves, to get anywhere.

The proposition that explanations cannot be reduced to individuals alone has now taken hold in the new institutional economics, notably in the work of Masahito Aoki (2001). He argues that always and unavoidably, analysis must start from individuals plus some institutions, however primitive.

The narrow methodological individualist has a problem of infinite regress: attempts to explain each emergent layer of institutions always rely on previous institutions and rules. These in turn have to be explained. The above arguments show that attempts to start simply from individuals must actually start from individuals plus social structures.

All theories must first build from elements which are taken as given. However, the particular problems identified here undermine any claim that the explanation of the emergence of institutions can start from some kind of institution-free ensemble of (rational) individuals in which there is supposedly no rule or institution to be explained. Consequently, the project to explain the emergence of institutions on the basis of given individuals runs into difficulties, particularly with regard to the conceptualization of the initial state of nature from which institutions are supposed to emerge.

Let us now turn to the broader version (b) of methodological individualism. The critique here is brief but no less devastating. Social structures are typically defined as interactive relations between individuals. These interactive relations may include social positions filled by individuals (such as prime minister, production manager, or sales representative). A social position is a specified social relationship with other individuals or social positions, which might in principle be occupied by alternative individuals. When an individual occupies a social position, he or she brings not only his or her own qualities or powers, but acquires additional qualities or powers associated with that position. Given this broad conception of social structure as interactive relations, (b) is definitionally equivalent to:

$(b+)$ social phenomena should be explained in terms of individuals and social structures.

The problem becomes one of labels rather than content. Although (b) and (b+) are acceptable statements, there is no good reason why they should be described as methodological individualism. It would be equally legitimate to describe them as 
'methodological structuralism' or 'methodological institutionalism'. All such descriptions are misleading. We always have to start from structures and individuals. There is no other viable explanatory strategy.

\section{Problems with Methodological Collectivism}

Because we always have to start from structures and individuals, prominent versions of 'methodological collectivism' and 'holism' have similarly to be rejected. Explanations entirely in terms of structures, cultures, or institutions are inadequate because they remove individual agency, and overlook the diverse characteristics among individuals in a population. If by contrast explanations are required to be in terms of structures and individuals, then we are back to a statement similar to $(\mathrm{b}+)$ above, and the description of this position as 'methodological collectivism' is equally one-sided and misleading.

Definitions of methodological collectivism are as problematic as those of methodological individualism. Examples or hints of methodological collectivism are found in Marxism, in the sociology of Émile Durkheim, and in structuralist or functionalist sociology. Defenders of Karl Marx point out that he acknowledged the role of the individual. Nevertheless, there are some highly misleading passages. For example, in a section of the German Ideology written in the 1840s, Karl Marx and Frederick Engels (1976, p. 59) wrote: 'The ruling ideas are nothing more than the ideal expressions of the dominant material relations'. The pitfall here is that ideas and volitions could be seen simply as expressions of the 'material relations' of the social structure. In the first volume of Capital Marx (1976, p. 989) described how the actions of the capitalist are 'no more' than the manifestation of capitalist structures. Similarly, in the third volume of Capital. Marx (1981, pp. 1019-20, emphasis added) wrote:

The principal agents of this mode of production itself, the capitalist and the wagelabourer, are as such simply embodiments and personifications of capital and wagelabour - specific social characters that the social production process stamps on individuals, products of these specific social relations of production.

The problem here is that explanations of individual agency seem to be conflated entirely upon 'material relations' and 'social structures', without recognition of individual diversity, cultural variation or discretionary possibilities. Although multiple interpretations of these passages are possible, Marx did not do enough to guard against a methodological collectivist interpretation.

Turning to Durkheim, he wrote in 1897 :

We believe it is a fruitful idea that social life must be explained not by the conception of it formed by those who participate in it, but by the profound causes which escape their consciousness. We also think that these causes must be sought mainly in the way in which individuals associating together are formed in groups. (Durkheim, 1982, p. 171)

A problem with this statement is that it does not explain how associations of individuals in groups explain social phenomena. Durkheim failed to elaborate and took refuge in unelaborated metaphorical phrases, such as 'collective forces' and 'social currents'. Durkheim (1982, p. 59, emphasis removed) defined his basic concept of the 'social fact':

The social fact is any way of acting, whether fixed or not, capable of exerting over the individual an external constraint ... which is general over the whole of a given society whilst having an existence of its own, independent of its individual manifestations. 
But there is a big difference between seeing such emergent phenomena as independent of any one individual, or external to all individuals. Again the quotation is ambiguous. Durkheim sometimes slid towards a methodological collectivism, where society and 'social forces' somehow stand above and manipulate all individuals.

Crucially, like Marxism, Durkheimian sociology lacks a developed micro-theory of how social structures affect, and are affected by, individual purposes or dispositions. Marx seemed to make psychology redundant, by declaring that the human essence was nothing more than the 'ensemble of the social relations'. More explicitly, Durkheim (1982, p. 129) banned psychology from social science with his famous declaration that 'every time a social phenomenon is directly explained by a psychological phenomenon, we may rest assured that the explanation is false.' The consequences of such neglects or prohibitions are highly damaging for social theory.

Both Durkheim and Marx lacked an adequate account of how individual dispositions are moulded. Such accounts must necessarily include psychological mechanisms. In their absence the temptation is to place the emphasis on social constraints, rather than on the additional reconstitution of individuals themselves. Explanations thus devolve to structures alone.

Many social theorists have criticized methodological collectivism for making the individual the mere puppet of social forces. In addition, it is argued here that the main problem is that methodological collectivism not only diminishes the individual, but also pays insufficient attention to the processes and mechanisms by which the individual is fundamentally altered. One consequence of conflating the individual into the structure is to lose sight, not simply of the individual, but also of the mechanisms of social power and influence that may help to reconstitute individual purposes or preferences. It may appear paradoxical, but only by rescuing the individual from its conflation into the social, can the social determination of individuality be fully appreciated.

Part of the solution is to bring psychology back into the picture. But strangely this is absent from much of social theory. There is very little psychology in Marxism, partly because the subject was so underdeveloped during Marx's time. Durkheim himself bears part of the responsibility for the exclusion of psychology from the main currents of twentieth century sociology. The influential Talcott Parsons (1937) was persuaded partly by Durkheim in this and other respects. Instead of psychology, and in a manner highly reminiscent of Durkheim, Parsons emphasized the power of social norms.

Some influential neoclassical economists also abandoned psychology at about the same time. Lionel Robbins (1932) recast economics as 'the science of choice'. Individual ends were taken as given, economics was to be all about the rational choice of appropriate means. Because individual preferences were taken as given, psychology no longer had a significant role in this reconstruction of the subject (Hodgson, 2001; Lewin, 1996).

After their common rejection of psychological and other underpinnings, economics and sociology went their separate ways. Proclamations of methodological individualism were more prominent in economics, and of methodological collectivism in sociology. The social sciences faced an apparent dilemma between an Adam Smith-like and incentive-driven view of action, on the one hand, and a Durkheim-like and norm-propelled view, on the other.

However, despite the century-long battle between methodological individualists and methodological collectivists, they have much more in common than is typically admitted. Methodological individualism conflates the social upon the individual, thus losing sight of key mechanisms of social influence, and is consequently impelled to take the purposes and 
preferences of the individual as given. Methodological collectivism conflates the individual upon society and thereby lacks an explanation or adequate recognition of how individual purposes or preferences may be changed. The explanatory moves are different but the results are similar in some vital respects: there is no adequate explanation of how social institutions may reconstitute individual purposes and preferences. Typically, both approaches disregard the value and role of psychology in the explanation of social phenomena. Both methodologies end up with a diminished concept of social power, and an analytical over-emphasis on overt coercion and constraint, rather than more subtle mechanisms of social influence.

\section{Reductionism and Reduction}

In their stronger formulations, methodological individualism and methodological collectivism are both different versions of (explanatory) reductionism, which refers to the more general doctrine that all aspects of a complex phenomenon should be completely explained in terms of one level, or type of unit. Promoting such a strong definition of reductionism, Elster (1983, pp. 20-4) wrote: 'Generally speaking, the scientific practice is to seek an explanation at a lower level than the explandum. ... The search for micro-foundations ... is in reality a pervasive and omnipresent feature of science.'

We can find many other versions of reductionism. Biological reductionism proposes that (social and other) phenomena should be explained solely in terms of biological characteristics. Physical reductionism requires that (biological, chemical or other) phenomena should be explained solely in terms of physics. Neurological reductionism proposes that psychic phenomena should be explained entirely in neurological terms. Methodological individualism pursues universal explanations of social phenomena in terms of individuals, and methodological collectivism the reverse.

Taking Elster-style reductionism to its extreme, it proposes that phenomena should be explained in terms of the lowest type of unit. This would not support methodological individualism, because we can go lower than the individual. It would suggest explanations of individual characteristics in terms of biology, and so on. But where would it stop? Ultimately it would suggest that all explanations should be reduced to subatomic physics. This would mean the dissolution of all sciences except subatomic physics. Everything would have to be brought down and explained in its terms. There would be no mechanics, no thermodynamics, no chemistry, no biology and no social science. All sciences would be reduced to one.

The reason why we have different sciences is that complete explanatory reduction is generally beyond reach, and multiple levels of explanation are both appropriate and powerful. Reductionist ambitions are at best, wildly optimistic, and at worst, dogmatic and diversionary.

Reductionism should also be distinguished from reduction. Emphatically, some degree of reduction to elemental units is inevitable and desirable in science. Even measurement is an act of reduction. Science cannot proceed without some dissection and some analysis of parts. However, although some reduction is unavoidable, complete analytical reductions are generally impossible. They are beset by analytical explosions in the number of combinations of elements; they are cursed by the ubiquitous phenomenon of complexity. Complete analytical reductions are rarely, if ever, achieved.

Reductionism cannot be wholly refuted in principle, because any explanatory deficit or limited explanatory reduction might sometime be remedied in the future. However, in no science are the canons of reductionism strictly enforced. Yet the sciences achieve results. 
Although we can never be sure than someday a missing explanation will be found, and a further explanatory reduction might be possible, there is sufficient evidence from the sciences to undermine the full reductionist dogma and to diminish reductionist ambitions. While reduction is a worthwhile and important aim, the sciences do not need full reductionism to qualify as science.

\section{Structuration Theory and Central Conflation}

The 'structuration theory' of Anthony Giddens (1984) is an attempt to steer a middle course between the extremes of both methodological individualism and methodological collectivism. ${ }^{5}$ He regards agent and structure as a 'duality' where both human subjects and social institutions are jointly constituted in and through recurrent practices, and where no element has ontological or analytical priority over the other. Structure and agency are mutually and symmetrically constitutive of each other.

Giddens (1982, p. 35) sees structures as 'recursively organized rules and resources'. Agency is both free and constrained. Human beings are reflective of, and reactive to, their circumstances, as well as being conditioned by them. Equally, instead of the prominent idea that the 'structural properties of society form constraining influences over action ... structuration theory is based on the proposition that structure is always both enabling and constraining' (Giddens, 1984, p. 169).

Agent and structure are regarded as different aspects of the same process. As Ian Craib (1992, pp. 3-4) put it in his commentary on Giddens, structure and agency are not treated as 'separate and opposing things in the world or as mutually exclusive ways of thinking about the world' but as 'simply two sides of the same coin. If we look at social practices in one way, we can see actors and actions; if we look at them in another way we can see structures.' Agent and structure are regarded as different facets of a unity. ${ }^{6}$

In contrast, several philosophers have proposed a layered ontology. The idea is commonplace in the philosophy of science: reality is irreducibly layered, with physical, molecular, organic, mental, human individual and social levels. ${ }^{7}$ Everything belongs to a level and each level has, within bounds, some autonomy and stability. However, each layer is linked to, and dependent upon, other layers. Such a stratified ontology is essentially absent from structuration theory. The individual and the social levels are conflated into the central ground of the recursive structure.

Essentially, in stratified ontologies, what separates one layer from another is the existence of emergent properties at the higher level. Units exist at higher levels that are not mere epiphenomena of lower-level units. A viable and irreducible hierarchical ontology depends upon the notion of emergent properties. A property may be said to be emergent if its existence

\footnotetext{
5 Related middle-way perspectives appear in organization studies, such as Chatman (1989) and Gerhart (2005).
}

\footnotetext{
6 A very similar view was promoted by the American sociologist Cooley (1902), who influenced American institutionalists (Hodgson, 2004).
}

${ }^{7}$ See, for example, Ward (1903), Sellars (1926), Bunge (1973), Bhaskar (1975) and Weissman (2000). 
and nature depend upon entities at a lower level, but the property is neither reducible to, nor predictable from, properties of entities found at the lower level. ${ }^{8}$

Giddens has no explicit layered ontology and makes no explicit use of the ideas of emergent properties. For Giddens $(1984$, p. 171) neural entities 'do not come together ex nihilo to form a new entity by fusion or association'. A consequence of Giddens's rejection of emergent properties is not only the rejection of a higher and social level of analysis with their own emergent properties, but also the analytical neglect of the natural and physical world as the essential substratum and context of human activity. Structuration theory is forced to accept a single level of reality, with nothing (social or otherwise) 'above' it, and nothing (natural or otherwise) 'below'. One consequence of this is the denudation of the concept of social structure. Another is the neglect of the natural and biological substratum of all human activity.

If structuration theory accepts a singular plane of being, then where is it? Giddens is explicit about this. For him, 'structure exists ... only in its instantiations of such [social] practices and as memory traces orienting the conduct of knowledgeable human agents' (Giddens, 1984, p. 17). Symptomatically, the formulation is repeated elsewhere: 'Structure exists only as memory traces, the organic basis of human knowledgeability, and as instantiated in action' (op. cit., p. 377). And again, in another work, for Giddens (1989, p. 256), structure 'exists only in a virtual way, as memory traces and as the instantiation of rules in the situated activities of agents.' An agent carries 'structural properties' in its memory, which may be transmitted through practice from one agent to another. Commentators on Giddens's theory thus observe that 'if structures have a locus of existence, it is in the heads of social actors' (Craib, 1992, p. 42). Richard Kilminster (1991, p. 96) made a similar point: "'structure" in Giddens' theory is internal to actors'.

A problem with the idea that social structure is entirely mental and internal is that it downplays the fact that structure consists not merely of persons or things, but also of interactive relations between persons, in a social and material context. Individuals may confront these structures, even if they do not have the memories, ideas or habits that are associated with them.

Giddens attempts to explain the persistence of social structures in terms of the centrality and persistence of routinized practice. For Giddens (1984, p. 60) routinization 'provides the master key'. But how can the existence of routinization itself be explained? Giddens's (p. 50) answer lies in his concept of 'ontological security'. This allegedly has its origins 'in basic anxiety-controlling mechanisms' that in turn are acquired by the individual as a result of 'predictable and caring routines established by parental figures'.

This argument has a strong functionalist flavour: the replication of routines is explained in terms of their function. The explanation for the persistence of routines is seen as the search for ontological security, which in turn results from the persistence of (parental) routines. However, no adequate explanation is given for the persistence of these 'caring routines established by parental figures'. These routines may be handed down from generation to

8 The concept of emergent properties was developed by the philosopher Lewes (1875), the psychologist and philosopher of biology Morgan (1923), and several others. For a history of the idea see Blitz (1992) and a recent defence see Humphreys (1997). Ward (1903) and others used the term 'creative synthesis' rather than 'emergent properties'. See Hodgson (2004) for a discussion. 
generation, but why would this be so? No adequate explanation of the origin or persistence of routines is given, and Giddens's discussion of ontological security does not provide it.

Routinization is an important idea but Giddens' s explanation of it is inadequate. A similar stress on routinization is found in the 'evolutionary economics' of Richard Nelson and Sidney Winter (1982). However, Giddens (1984, pp. 228-43) has been a critic of evolutionism in the social sciences and has rejected 'evolutionary' ideas in that domain. ${ }^{9}$

In their critiques of Giddens, Roy Bhaskar (1989) and Margaret Archer (1995) insist that human agents and structures are not different aspects of the same things or processes, but different entities. Although structures depend for their existence upon individuals, they are different and distinct. This separation stems from the fact that, for any particular actor, social structure always exists prior to her engagement with the world. Bhaskar (1989, p. 36) wrote that 'people do not create society. For it always pre-exists them and is a necessary condition for their activity.' Hence any given individual is preceded by the social structures into which they are born. As Archer (1995, p. 72) put it: 'This is the human condition, to be born into a social context (of language, beliefs and organization) which was not of our making'. She criticized Giddens's structuration theory as a 'central conflation' because it conflates structure and agency into processes acting together at a single level.

However, the differentiation of structure from agent is valid if structure is seen as external to any given individual, but not if it is regarded as external to all individuals. Structure does not exist apart from all individuals, but it may exist apart from any given individual. Unless this distinction is given sufficient stress, the concept of structure may be reified.

\section{A Missing Link}

While the Archer-Bhaskar critical realist approach is an important advance, it has some problems. While there is an account of structural change, there is as yet no account of how individuals are changed. We are told how structures evolve, but there is no parallel explanation of the changes to individuals. Individual agency is rightly retained and emphasized. Bhaskar (1989, p. 80) and other critical realists argue that 'intentional human behaviour is caused' but 'it is always caused by reasons, and that it is only because it is caused by reasons that it is properly characterized as intentional.' But in critical realism there is no adequate explanation of the causes of reasons or beliefs. So far, the account of agency in critical realism is incomplete (Faulkner, 2002).

Bhaskar (1975, pp. 70-1) endorses an 'ubiquity determinism', meaning that every event is caused. Yet critical realism has so far failed to apply this universal principle to individual reasons or beliefs. It recognizes that beliefs are part of social reality, but gives no account of the cultural, psychological or physiological causes of beliefs or reasons themselves. In critical realism so far there is no explanation of how individual agents acquire or change their beliefs,

\footnotetext{
9 Giddens (1979, p. 233) described evolution as 'social change as the progressive emergence of traits that a particular type of society is presumed to have within itself from its inception'. This non-Darwinian and 'unfolding' conception of evolution is very different from the evolutionary economics of Veblen (1919) or of Nelson and Winter (1982). These latter accounts see economic evolution as an ongoing, imperfect and nonteleological process of competitive selection, acting upon a varied population of institutions, habits, customs and routines. Evolution in this conception is not necessarily progressive, and is invulnerable to Giddens's critique.
} 
reasons, purposes or preferences. The possibility of such changes may be admitted, but as yet there is no indication in critical realism of how such changes may be explained.

The position of Bhaskar (1989) and Archer (1995) is a case of non-conflation but incomplete explanation. There is no explanation, even in principle, of the origin of reasons or beliefs. However, this limitation is not unique to critical realism: many other approaches in social science share this defect.

With this omission, a temptation is to adopt a schema in which structure somehow channels individual activity with a sufficiency to explain it, thus putting the emphasis on the role of structures as constraints on individuals. ${ }^{10}$ Without an account of how individual intentions or preferences may change, a danger is to rely on structural constraints to do the main work of explaining human behaviour. The disconnection of agency and structure may end up explaining the individual solely by reference to structure, thus conflating the individual into the structure, as criticized above.

The opposite temptation is to tack the subjective preferences or purposes of individuals as the rock bottom - the ultimate explanatory factors. Without an analysis of how preferences, purposes or beliefs are caused, the temptation is to revert to either individualist or structuralist extremes.

Taking the given individual as the fundamental unit of analysis, many economists reject the idea of explaining individual preferences. For example, Friedrich Hayek (1948, p. 67) wrote: "If conscious action can be "explained," this is a task for psychology but not for economics ... or any other social science'. Like many others, Hayek shunned one of the central problems of social science - to explain human motivation.

Likewise, methodologically collectivist attempts to explain individuals exclusively in terms of social structures also typically fail to provide an adequate account of human motivation. It is often simply assumed that roles or cultures or institutions affect individuals, without explaining how such social structures work their magic on individual motivations. Some have turned to behaviourist psychology, in the belief that its mechanisms of stimulus and response provide the answer. But behaviourism fails to address the inner springs of cognition and deliberation, overlooks the fact that beliefs are part of social reality. It makes the agent a puppet of its social environment.

In contrast, with a causal and psychological explanation of how structures can affect or mould individual purposes or preferences, then the role of the individual can be placed alongside that of structure and becomes part of a fuller, two-way explanation. The spiral of causation from structure to individual, and from individual to structure, does not deny individuality; but it places the individual in his or her proper place within the ongoing process of social transformation.

\section{The Nature and Role of Habits}

What is required is a framework within which the transformation of both individuals and structures can be explained. This approach must involve explanations of possible causal interaction and reconstitution, from both individual to structure and from structure to

\footnotetext{
10 An example is the Marxian idea that the behaviour of the capitalist is determined entirely and with little variation by the need to survive in a competitive market. For a critique see Hodgson (1999).
} 
individual. This would mean an explanation of the evolution of individual purposes and beliefs, as well as an explanation of the evolution of structures. Preferences or purposes would be endogenously formed. Their co-evolution must be examined, without conflating one into the other. Such an evolutionary analysis provides the means by which social theory may escape from its unsustainable dichotomies and make further progress.

Pragmatist philosophers and institutional economists in the Veblenian tradition argue that institutions work only because the rules involved are embedded in prevalent habits of thought and behaviour (Veblen, 1899; Dewey, 1922; Joas, 1996; Twomey, 1998; Kilpinen, 2000). In the social sciences, the concept of habit was robbed of most of its significance as a result of the rise of behaviourist psychology. Failing to acknowledge propensities, behaviourism treated habit as behaviour. In contrast, Veblen and the pragmatist philosophers regarded habit as an acquired proclivity or capacity, which may not be actually expressed in current behaviour. As John Dewey (1922, p. 42) put it: 'The essence of habit is an acquired predisposition to ways or modes of response.' Repeated behaviour is important in establishing a habit. But habit and behaviour are not the same. If we acquire a habit we do not necessarily use it all the time. Many habits are unconscious. Habits are submerged repertoires of potential thought or behaviour, to be triggered by an appropriate stimulus or context.

Many have difficulty with the idea of habit as a disposition. A source of the problem is a reluctance to remove reason and belief from the exclusive driving seat of human action. The 'mind-first' conception of action pervades social science. If habits affect behaviour then it is wrongly feared that reason and belief will be dethroned. The concern is that volition would be replaced by mechanism. However, from a pragmatist perspective, reasons and beliefs themselves depend upon habits of thought. Habits act as filters of experience and the foundations of intuition and interpretation. Habit is the grounding of both reflective and nonreflective behaviour. This does not make belief, reason or will any less important or real.

The formation of habits requires repeated behaviours, which sometimes are triggered by innate dispositions, and often result from the propensity to imitate others in social conditions with guiding constraints. Repeated behaviour leads to the formation of habits of thought or action. Habit is the psychological mechanism that forms the basis of much rule-following behaviour.

For a habit to acquire the status of a rule, it has to acquire some inherent normative content, to be potentially codifiable, and to be prevalent among a group. The prevailing rule structure provides incentives and constraints for individual actions. Channelling behaviour in this way, accordant habits are further developed and reinforced among the population. Hence the rule structure helps to create habits and preferences that are consistent with its reproduction. Habits are the constitutive material of institutions, providing them with enhanced durability, power and normative authority. In turn, by reproducing shared habits of thought, institutions create strong mechanisms of conformism and normative agreement.

As Charles Sanders Peirce (1878, p. 294) declared, the 'essence of belief is the establishment of habit'. Habit is not the negation of deliberation, but its necessary foundation. Reasons and beliefs are often the rationalizations of deep-seated feelings and emotions that spring from habits laid down by repeated behaviours (Kilpinen, 2000; Ouellette and Wood, 1998; Wood et al., 2002). Such dispositions and emotions are integral to decision-making (Damasio, 1994). This interplay of behaviour, habit, emotion and rationalization helps to explain the normative power of custom in human society.

Habits are acquired in a social context and not genetically transmitted. By accepting the foundational role of habit in sustaining rule-following behaviour, we can begin to build an 
alternative ontology of institutions, in which we avoid the conceptual problems of an account based primarily on intentionality. This is not to deny the importance of intentionality, but to regard it as a consequence as much as a cause, and to place it in the broader and ubiquitous context of other, non-deliberative behaviours. ${ }^{11}$

\section{Reconstitutive Downward Causation}

Everyone accepts that institutions depend for their existence upon individuals, and it is sometimes possible for individuals to change institutions. This could be described as 'upward causation'. More controversially, by structuring, constraining and enabling individual behaviours, institutions have the power to mould the dispositions and behaviours of agents in fundamental ways; they have a capacity to change aspirations, instead of merely enabling or constraining them. Habit is the key mechanism in this transformation. Institutions are social structures that can involve reconstitutive downward causation, acting to some degree upon individual habits of thought and action (March and Olsen, 1989; Hodgson, 2003, 2004). ${ }^{12}$

The existence of reconstitutive downward causation does not mean that institutions directly, entirely or uniformly determine individual aspirations, merely that there can be significant downward effects. Insofar is institutions lead to regularities of behaviour, concordant habits are laid down among the population, leading to congruent purposes and beliefs. In this way the institutional structure is further sustained.

Because institutions simultaneously depend upon the activities of individuals and constrain and mould them, through this positive feedback they have strong self-reinforcing and selfperpetuating characteristics. Institutions are perpetuated not simply through the convenient coordination rules that they offer. They are also perpetuated because they confine and mould individual aspirations, and create a foundation for their existence upon the many individual minds that they taint with their conventions.

This does not mean, however, that institutions stand separately from the group of individuals involved; institutions depend for their existence on individuals. Nevertheless, any single individual is born into a pre-existing institutional world, which confronts him or her with its rules and norms. The institutions that we face reside in the dispositions of other individuals, but also depend on the structured interactions between them, often also involving material artefacts or instruments. History provides the resources and constraints, in each case both material and cognitive, in which we think, act and create.

Accordingly, institutions are simultaneously both objective structures 'out there', and subjective springs of human agency 'in the human head'. Institutions are in this respect like Klein bottles: the subjective 'inside' is simultaneously the objective 'outside'. The institution thus offers a link between the ideal and the real. The twin concepts of habit and institution help to overcome the philosophical dilemma between realism and subjectivism in social science. Actor and institutional structure, although distinct, are thus connected in a circle of mutual interaction and interdependence.

11 The dispositional treatment of habit here is broadly consistent with Vanberg's (2002) concept of 'programbased' activity, which he insists must be rendered consistent with our knowledge of human evolution.

12 The term 'downward causation' has its own history (Campbell, 1974; Sperry, 1991, Emmeche et al. 2000). The meaning of the added word 'reconstitutive' is explained below. 
The crucial role of habit is illuminated in what is perhaps the first computer simulation of extensive interaction between agents and structures, where the preferences of agents are altered by institutional circumstances just as institutions are developed by agents (Hodgson and Knudsen, 2004a). This is an agent-based simulation of the emergence of a traffic convention to drive on the left or the right side of the road. The simulations show that strength of habit and processes of habituation play a vital role alongside rational deliberation and selection pressure. This not only raises important questions concerning the role of habit in decision-making but also it challenges the frequent assumption that preference functions should always be taken entirely as exogenously given.

Habit removes some actions from conscious deliberation. However, the model suggests that there is something more to habit than economizing on decision-making. The model shows that a crucial role played by habit is to build up and reinforce an enduring disposition in each agent, concerning the appropriate side of the road on which to drive. The development of habits amounts to an element of endogenous preference formation. A sequence of repeated behaviours creates in each agent a habitual predilection, which can stimulate a 'belief' or 'conviction' that a particular behavior is appropriate. The evolution of a convention in the model depends largely on one set of stubborn 'beliefs' triumphing over the other. Once a stable convention forms, it is encoded in the dispositions of the majority and it can resist the intrusion of a substantial amount of erratic behavior. Accordingly, habit is a means by which social conventions and institutions are formed and preserved.

The model also provides a framework to consider the nuanced interpretations and meanings of the concept of 'downward causation', which has weak and strong forms (Sperry, 1991; Emmeche et al., 2000; Hodgson, 2003). In our model, this weaker form of downward causation is clearly present, where evolutionary selection acts on the population of agents, causing a shift in the characteristics of the population as a whole. For any individual agent, evolutionary selection does not cause a change in the values of the fixed parameters.

In our model, a stronger form of downward causation is also present. More and more surviving cars develop the habit to drive on the left or the right, according to the emerging convention. Habits are part of the preferences of each agent and they change with experience. In this way, emerging and enduring systemic properties reconstitute 'downwards' the preferences of the agent. This causal mechanism amounts to reconstitutive downward causation. Part of the achievement here is to show that both forms of downward causation can be represented in an agent-based model.

Reconstitutive downward causation does not mean that social laws or forces can overturn the principles governing the operation of human mental and physical activity at the level of the individual. Nobel Laureate Roger Sperry (1991, p. 230) insists on a similar condition: 'the higher-level phenomena in exerting downward control do not disrupt or intervene in the causal relations of the downward-level component activity'. This could usefully be termed Sperry's Rule. It ensures that emergence, although it is associated with emergent causal powers at a higher level, does not generate multiple types or forms of causality at any single level. Any emergent causes at higher levels exist by virtue of lower-level causal processes. ${ }^{13}$

Adherence to Sperry's Rule excludes any version of methodological collectivism or holism where an attempt is made to explain individual dispositions or behaviour entirely in terms of 13 This version of 'reconstitutive' downward causation is consistent with the 'medium' conditions of viability
advanced by Emmeche et al. (2000). 
institutions or other system-level characteristics. Instead, Sperry's Rule obliges us to explain particular human behaviour in terms of causal processes operating at the individual level, such as individual aspirations, dispositions or constraints. Where higher-level factors enter, it is in the more general explanation of the system-wide processes giving rise to those aspirations, dispositions or constraints.

Another crucial point is to recognize the specific mechanism by which reconstitutive downward causation operates. It is on habits, rather than merely on behavior, intentions or other preferences. Clearly, the definitional distinction between habit (as a propensity or disposition) and behavior (or action) is essential to make sense of this statement.

The existence of a viable mechanism of reconstitutive downward causation contrasts with other, untenable 'top down' explanations in the social sciences where there are unspecified 'cultural' or 'economic' forces controlling individuals. Crucially, the mechanism of reconstitutive downward causation that is outline here affects the dispositions, thoughts and actions of human actors. Hence this model illustrates the Veblenian process by which emergent institutions work on individual habits and give rise to new preferences and intentions.

\section{Concluding Remarks}

Much of the discussion above has focused on institutions, rather than the more general form of structures. Because institutions are rule systems of some durability, they permit the formation of habits and open up the possibility of reconstitutive downward causation. In turn, organizations are a special type of institution, with additional characteristics. In what respect do these additional characteristics enhance the picture, and what are some of the implications?

Organizations are bounded institutions with a relatively high degree of cohesion. ${ }^{14}$ Their characteristics of membership, sovereignty and responsibility enhance the possibilities for more intensive interactions between individuals and organizations. Organizations such as the family and the firm affect our lives in intimate and profound ways. They carry a richer repertoire of mechanisms and opportunities for creating habits and thereby altering preferences and beliefs. The other side of the coin is that organizations themselves depend on the existence of a complex of habits relating to rules concerning membership, sovereignty and responsibility.

A practical outcome is that any attempt to create or develop an organization, or to change its strategy, partly but necessarily involves the development of accordant individual habits. The psychological mechanism of habit is something much more specific than the often vague concept of organizational culture. An upshot of the approach promoted here is to focus more specifically on the processes of habit formation.

Nelson and Winter (1982) and others emphasize that organizations embody routines involving skills that lead to patterns of behaviour. A routine is a generative structure or capacity within an organization. Routines are organizational dispositions to energize conditional patterns of behaviour within an organized group of individuals, involving sequential responses to cues.

\footnotetext{
14 Formal conditions of such cohesion and some implications for the theory of organizational evolution are laid out in Hodgson and Knudsen (2004b).
} 
What are the psychological mechanisms involved? Psychology makes a distinction between procedural and other, more cognitive forms of memory, such as semantic, episodic or declarative memory (Cohen and Bacdayan, 1994). Procedural memory is triggered by preceding events and stimuli. Organizational routines depend upon a structured group of individuals, each with habits of a particular kind, where many of these habits depend upon procedural memory. ${ }^{15}$

The behavioural cues by some members of a structured assembly of habituated individuals triggers specific habits in others. Hence various individual habits sustain each other in an interlocking structure of reciprocating individual behaviours. Together these behaviours take on collective qualities associated with teams. Both individuals and structures are involved throughout. The organization or group provides a structured social and physical environment for each individual, including rules and norms of behaviour, of both the explicit and the informal kind. This environment is made up of the other individuals, the relations between them and the technological and physical artefacts that they may use in their interactions. This social and physical environment enables, stimulates and channels individual activities, which in turn can help trigger the behaviour of others, produce or modify some artefacts, and help to change or replicate parts of this social and physical environment.

Individuals have habits; groups have routines. Routines are the organizational analogue of habits. But routines do not simply refer to habits that are shared by many individuals in an organization or group. If this were the case there would be no need for the additional concept of a routine. Routines are irreducible to habits alone: they are organizational meta-habits, existing on a substrate of habituated individuals in a social structure. Routines are one ontological layer above habits themselves.

Partly because of procedural memory, organizations can have important additional properties and capacities that are not possessed by individuals, taken severally (Argyris and Schön, 1996; Levitt and March, 1988). The organization provides the social and physical environment that is necessary to enable specific activities, cue individual habits and deploy individual memories. If one person leaves the organization and is replaced by another, then the new recruit may have to learn the habits that are required to maintain specific routines. Just as the human body has a life in addition to its constituent cells, the organization thus has a life in addition to its members. Generally, the organizational whole is greater than the sum of the properties its individual members, taken severally. The additional properties of the whole stem from the structured relations and causal interactions between the individuals involved. This is a central proposition in the emergentist tradition of philosophy and social theory (Blitz, 1992; Kontopoulos, 1993; Hodgson, 2004; Wiessman, 2000).

Organizations are relatively cohesive entities that often compete with other organizations for scarce resources. Organizational evolution involves the development and reproduction of organizational routines and accordant individual habits. Following evolutionary economists such as Richard Nelson and Sidney Winter (1982) and organization scientists such as Howard Aldrich (1999) this opens up the possibility of an evolutionary approach. Despite an aversion among some social scientists to ideas taken from biology, it has been demonstrated that evolutionary ideas are extremely powerful in this regard. Veblen $(1899,1919)$ was one of the first social scientists to pioneer an evolutionary approach with a strong Darwinian inspiration. At a suitably abstract level, evolutionary theory offer a general framework for understanding

\footnotetext{
15 See Becker (2004) for a review of the literature on routines.
} 
both persistence and change in a population of units, including organizations. It is here that evolutionary economics, Veblenian institutionalism and organization science all converge, creating a lively agenda for future enquiry. ${ }^{16}$

16 Nevertheless, important differences of viewpoint exist. Aldrich (1999) embraces Darwinian terminology, but it is implicit rather than explicit in Nelson and Winter (1982). Hodgson and Knudsen (2006) and others argue that a Darwinian framework is essential to understand the evolution of organizations. Hodgson and Knudsen (forthcoming) also deal with the problems and ambiguities surrounding the misleading use of the 'Lamarckian' label to describe socio-economic evolution. This has a bearing on contributions to organization science, including Hannan and Freeman (1989) and Usher and Evans (1996). 


\section{References}

Aldrich, Howard E. (1999) Organizations Evolving (London: Sage).

Aoki, Masahiko (2001) Toward a Comparative Institutional Analysis (Cambridge, MA: MIT Press).

Archer, Margaret S. (1995) Realist Social Theory: The Morphogenetic Approach (Cambridge: Cambridge University Press).

Argyris, Chris and Schön, Donald A. (1996) Organizational Learning II: Theory, Method, and Practice (Reading, MA: Addison-Wesley).

Arrow, Kenneth J. (1994) 'Methodological Individualism and Social Knowledge', American Economic Review (Papers and Proceedings), 84(2), May, pp. 1-9.

Becker, Markus C. (2004) 'Organizational Routines: A Review of the Literature', Industrial and Corporate Change, 13(4), pp. 643-77.

Bhaskar, Roy (1975) A Realist Theory of Science (Leeds: Leeds Books).

Bhaskar, Roy (1989) The Possibility of Naturalism: A Philosophic Critique of the Contemporary Human Sciences, 2nd edn. (Brighton: Harvester).

Blitz, David (1992) Emergent Evolution: Qualitative Novelty and the Levels of Reality (Dordrecht: Kluwer).

Bogdan, Radu (2000) Minding Minds: Evolving a Reflexive Mind in Interpreting Others (Cambridge, MA: MIT Press).

Bunge, Mario A. (1973) Method, Model and Matter (Dordrecht, Holland: Reidel).

Campbell, Donald T. (1974) “"Downward Causation” in Hierarchically Organized Biological Systems', in Ayala, Francisco J. and Dobzhansky, Theodosius (eds) (1974) Studies in the Philosophy of Biology (London, Berkeley and Los Angeles: Macmillan and University of California Press), pp. 179-86.

Chatman, Jennifer A. (1989) 'Improving Interactional Organizational Research: A Model of Person-Organization Fit', Academy of Management Review, 14(3), pp. 333-49

Cohen, Michael D. and Bacdayan, Paul (1994) 'Organizational Routines are Stored as Procedural Memory - Evidence from a Laboratory Study', Organization Science, 5(4), November, pp. 554-68.

Cooley, Charles Horton (1902) Human Nature and the Social Order, $1^{\text {st }}$. edn. (New York: Scribner's).

Craib, Ian (1992) Anthony Giddens (London: Routledge).

Damasio, Antonio R. (1994) Descartes' Error: Emotion, Reason, and the Human Brain (New York: Putnam).

Dewey, John (1922) Human Nature and Conduct: An Introduction to Social Psychology, 1st edn. (New York: Holt).

Douglas, Mary T. (1986) How Institutions Think (London and Syracuse: Routledge and Kegan Paul and Syracuse University Press). 
Durkheim, Émile (1982) The Rules of Sociological Method, translated from the French edition of 1901 by W. D. Halls with an introduction by Steven Lukes (London: Macmillan).

Elster, Jon (1982) 'Marxism, Functionalism and Game Theory', Theory and Society, 11(4), pp. $453-82$.

Elster, Jon (1983) Explaining Technical Change (Cambridge: Cambridge University Press).

Emmeche, Claus, Køppe, Simo and Stjernfelt, Frederik (2000) 'Levels, Emergence, and Three Versions of Downward Causation', in Andersen, Peter Bøgh, Emmeche, Claus, Finnemann, Niels Ole and Christiansen, Peder Voetman (eds) (2000) Downward Causation: Minds, Bodies and Matter (Aarhus: Aarhus University Press), pp. 13-34.

Faulkner, Philip (2002) 'Some Problems With the Conception of the Human Subject in Critical Realism', Cambridge Journal of Economics, 26(6), November, pp. 739-51.

Field, Alexander J. (1979) 'On the Explanation of Rules Using Rational Choice Models', Journal of Economic Issues, 13(1), March, pp. 49-72.

Fleck, Ludwik (1979) Genesis and Development of a Scientific Fact, translated by F. Bradley and T. J. Trenn from the German edition of 1935 (Chicago: University of Chicago Press).

Gerhart, Barry (2005) 'The (Affective) Dispositional Approach to Job Satisfaction: Sorting out the Policy Implications', Journal of Organizational Behavior, 26(1), pp. 79-97.

Giddens, Anthony (1979) Central Problems in Social Theory (Berkeley and Los Angeles: University of California Press).

Giddens, Anthony (1982) Profiles and Critiques in Social Theory (London: Macmillan).

Giddens, Anthony (1984) The Constitution of Society: Outline of the Theory of Structuration (Cambridge: Polity Press).

Giddens, Anthony (1989) 'A Reply to My Critics', in Held, David and Thompson, John B. (1989) Social Theory of Modern Societies: Anthony Giddens and His Critics (Cambridge: Cambridge University Press), pp. 249-301.

Hannan, Michael T. and Freeman, John (1989) Organizational Ecology (Cambridge, MA: Harvard University Press).

Hayek, Friedrich A. (1948) Individualism and Economic Order (London and Chicago: George Routledge and University of Chicago Press).

Hodgson, Geoffrey M. (1988) Economics and Institutions: A Manifesto for a Modern Institutional Economics (Cambridge and Philadelphia: Polity Press and University of Pennsylvania Press).

Hodgson, Geoffrey M. (1999) Economics and Utopia: Why the Learning Economy is not the End of History (London and New York: Routledge).

Hodgson, Geoffrey M. (2001) How Economics Forgot History: The Problem of Historical Specificity in Social Science (London and New York: Routledge).

Hodgson, Geoffrey M. (2003) 'The Hidden Persuaders: Institutions and Individuals in Economic Theory', Cambridge Journal of Economics, 27(2), March, pp. 159-75.

Hodgson, Geoffrey M. (2004) The Evolution of Institutional Economics: Agency, Structure and Darwinism in American Institutionalism (London and New York: Routledge). 
Hodgson, Geoffrey M. (2006) 'What Are Institutions?', Journal of Economic Issues, 40(1), March, pp. 1-25.

Hodgson, Geoffrey M. and Knudsen, Thorbjørn (2004a) 'The Complex Evolution of a Simple Traffic Convention: The Functions and Implications of Habit', Journal of Economic Behavior and Organization, 54(1), pp. 19-47.

Hodgson, Geoffrey M. and Knudsen, Thorbjørn (2004b) 'The Firm as an Interactor: Firms as Vehicles for Habits and Routines', Journal of Evolutionary Economics, 14(3), July, pp. 281-307.

Hodgson, Geoffrey M. and Knudsen, Thorbjørn (2006) 'Why We Need a Generalized Darwinism: and Why a Generalized Darwinism is Not Enough', Journal of Economic Behavior and Organization (forthcoming).

Hodgson, Geoffrey M. and Knudsen, Thorbjørn (forthcoming) 'Dismantling Lamarckism: Why Descriptions of Socio-Economic Evolution as Lamarckian are Misleading', Journal of Evolutionary Economics (forthcoming).

Humphreys, Paul (1997) 'How Properties Emerge', Philosophy of Science, 64(1), March, pp. $1-17$.

Joas, Hans (1996) The Creativity of Action (Chicago: University of Chicago Press).

Kilminster, Richard (1991) 'Structuration Theory as a World-View', in Christopher G. A. Bryant and David Jary (eds) (1991) Giddens’ Theory of Structuration: A Critical Appreciation (London: Routledge), pp. 74-115.

Kilpinen, Erkki (2000) The Enormous Fly-Wheel of Society: Pragmatism's Habitual Conception of Action and Social Theory (Helsinki: University of Helsinki).

Kontopoulos, Kyriakos M. (1993) The Logics of Social Structure (Cambridge: Cambridge University Press).

Lachmann, Ludwig M. (1969) 'Methodological Individualism and the Market Economy', in Streissler, Erich W. (ed.) (1969) Roads to Freedom: Essays in Honour of Friedrich A. von Hayek (London: Routledge and Kegan Paul), pp. 89-103.

Levitt, Barbara and March, James G. (1988) 'Organizational Learning', Annual Review of Sociology, 14, pp. 319-40.

Lewes, George Henry (1875) Problems of Life and Mind: First Series: The Foundations of a Creed, vol. 2 (London: Trübner).

Lewin, Shira B. (1996) 'Economics and Psychology: Lessons for Our Own Day From the Early Twentieth Century', Journal of Economic Literature, 34(3), September, pp. 1293323.

Lukes, Steven (1973) Individualism (Oxford: Basil Blackwell).

March, James G. and Olsen, Johan P. (1989) Rediscovering Institutions: The Organizational Basis of Politics (New York: Free Press).

Marx, Karl (1976) Capital, vol. 1, translated by Ben Fowkes from the fourth German edition of 1890 (Harmondsworth: Pelican).

Marx, Karl (1981) Capital, vol. 3, translated by David Fernbach from the German edition of 1894 (Harmondsworth: Pelican). 
Marx, Karl and Engels, Frederick (1976) Karl Marx and Frederick Engels, Collected Works, Vol. 5, Marx and Engels: 1845-1847 (London: Lawrence and Wishart).

Mead, George Herbert (1934) Mind, Self and Society - From the Standpoint of a Social Behaviorist (Chicago: University of Chicago Press).

Morgan, Conwy Lloyd (1923) Emergent Evolution (London: Williams and Norgate).

Mouzelis, Nicos (1995) Sociological Theory: What Went Wrong? Diagnosis and Remedies (London and New York: Routledge).

Nelson, Richard R. and Winter, Sidney G. (1982) An Evolutionary Theory of Economic Change (Cambridge, MA: Harvard University Press).

Ostrom, Elinor (2005) Understanding Institutional Diversity (Princeton: Princeton University Press).

Ouellette, Judith A. and Wood, Wendy (1998) 'Habit and Intention in Everyday Life: The Multiple Processes by which Past Behavior Predicts Future Behavior', Psychological Bulletin, 124, pp. 54-74.

Peirce, Charles Sanders (1878) 'How to Make Our Ideas Clear', Popular Science Monthly, 12, January, pp. 286-302.

Parsons, Talcott (1937) The Structure of Social Action, 2 vols (New York: McGraw-Hill).

Popper, Karl R. (1945) The Open Society and Its Enemies, 2 vols (London: Routledge and Kegan Paul).

Robbins, Lionel (1932) An Essay on the Nature and Significance of Economic Science, 1st edn. (London: Macmillan).

Searle, John R. (2005) 'What is an Institution?', Journal of Institutional Economics, 1(1), June, pp. 1-22.

Sellars, Roy Wood (1926) The Principles and Problems of Philosophy (New York: Macmillan).

Sperry, Roger W. (1991) 'In Defense of Mentalism and Emergent Interaction', Journal of Mind and Behavior, 12(2), pp. 221-46.

Twomey, Paul (1998) 'Reviving Veblenian Economic Psychology', Cambridge Journal of Economics, 22(4), July, pp. 433-48.

Udéhn, Lars (2001) Methodological Individualism: Background, History and Meaning (London and New York: Routledge).

Usher, John M. and Evans, Martin G. (1996) 'Life and Death Along Gasoline Alley: Darwinian and Lamarckian Processes in a Differentiating Population', Academy of Management Journal, 39(5), October, pp. 1428-66.

Vanberg, Viktor J. (2002) 'Rational Choice versus Program-Based Behavior: Alternative Theoretical Approaches and Their Relevance for the Study of Institutions', Rationality and Society, 14(1), Summer, pp. 7-53.

Veblen, Thorstein B. (1899) The Theory of the Leisure Class: An Economic Study in the Evolution of Institutions (New York: Macmillan).

Veblen, Thorstein B. (1914) The Instinct of Workmanship, and the State of the Industrial Arts (New York: Macmillan). 
Veblen, Thorstein B. (1919) The Place of Science in Modern Civilization and Other Essays (New York: Huebsch).

Ward, Lester Frank (1903) Pure Sociology: A Treatise On the Origin and Spontaneous Development of Society (New York and London: Macmillan).

Weissman, David (2000) A Social Ontology (New Haven, CT: Yale University Press).

Wood, Wendy, Quinn, Jeffrey M. and Kashy, D. (2002) 'Habits in Everyday Life: Thought, Emotion, and Action', Journal of Personality and Social Psychology, 83, pp. 1281-97. 